\title{
FACULTY SOCIAL LEARNING AND ENRICHMENT OF MIS COURSES
}

\author{
Thomas L. Ngo-Ye, Alabama State University, tngoye@alasu.edu \\ Bob McNeal, Alabama State University, bobmcneal@alasu.edu \\ Dexter Gittens, Alabama State University, DGittens@alasu.edu
}

\begin{abstract}
We propose the faculty social learning (FSL) approach, where faculties proactively engage in social encounters with useful contacts (returning adult students with professional experiences, school alumni, college IT staffs, local higher education faculties, and local business and IT professionals) to learn new ideas, technologies, trends, and knowledge for the purpose of sharing them with students to enrich MIS courses. We can acquire new knowledge via informal conversations with contacts, and inviting experts as guest speakers to our classes. Moreover, out expertise can be improved through participation in local professional, and social events where new contacts can be made and exposure to new technologies can be determined. We make a case for FSL based on adult self-directed learning theory, motivation theory, and social learning theory. We give detailed guide on how to conduct FSL from our first-hand experience. We also report our own examples of FSL and lessons learned.
\end{abstract}

Keywords: Faculty Social Learning (FSL), Enrich MIS Courses, Motivation Theory, Social Learning Theory, Faculty Professional Development

\section{INTRODUCTION}

The field of Management Information Systems (MIS) is constantly subject to change, often rapidly. Innovative technologies driven by cutting edge MIS approaches result in new business processes and new thinking. This continuously changing landscape poses a practical challenge to MIS faculties. How can faculties keep their knowledge current and updated so that teaching is relevant to the contemporary business world? Conventional approaches for faculty continuing education include new texts, faculty development activities such as conferences and seminars, and self-learning through YouTube and Google searches. In this study, we propose a new approach - faculty social learning (FSL), in which faculty members engage in a wide range of social learning activities, both on the local campus and in other venues. For example, local campus FSL would include college committee meetings, casual conversations with students and alumni, guest speaker's presentations to classes, "IT Club" meetings, and conversations with college IT staffs. External meetings with faculty from local and regional higher education institutions, as well as various local and regional IT and business events would add to the exposure. Through these social learning activities, faculties can stay current and connected, and learn about new developments in both technology and the business world. New knowledge and insight, would support faculty efforts to make MIS courses more interesting, exciting, and relevant to students. This innovative approach of teaching will enrich MIS courses resulting in more engaged students, not only those majoring in MIS, but also students majoring in other business fields.

\section{Conventional Knowledge Sources for Teaching MIS}

Faculties build their knowledge base in their field of expertise from their formal undergraduate education, graduate education, and research efforts. In addition to this, many MIS faculty members enhance their knowledge as a result of professional career activities as well as personal experiences related to MIS. Due to different backgrounds, environments, social networks, and personal interest in different areas of MIS, each MIS faculty has his/her own unique knowledge-base, skill-set, and strength. However, the ever-changing field of MIS mandates that MIS faculties be life-long learners in order to acquire new knowledge and skills for teaching. We identify three conventional knowledge sources that faculties can lean on for continuous learning: 1) textbooks, 2) formal external training, and 3) YouTube and google. 


\section{Issues in Information Systems}

Volume 18, Issue 4, pp. 158-168, 2017

\section{Textbooks}

Books in general, and textbooks in particular, are major sources of new knowledge. Textbooks are generally of reliable quality because of the established process of peer-review and publisher's editing practices which they must go through. We suggest that MIS faculties should use textbooks from well-known publishers and reputable textbook authors to assure textbook quality. In addition, MIS faulty should always adopt the latest editions of textbooks with the most current knowledge in the field along with discussions of current technology. It is also important that textbook business cases incorporate the latest technological issues. For example, faculty responsible for the course "Introduction to Database Management" should adopt Database concepts, $8^{\text {th }}$. Ed. by Kroenke, et al (2018) as the required textbook. Instructor materials, provided by textbook publishers, are also useful for enhancing the presentation of concepts and student understanding. Generally, publishers provide materials that are compatible with the most current text edition. Overall, textbooks represent a reliable, high-quality, and efficient knowledge source. However, due to the rapid changing nature of MIS and the lengthy lead time of publishing a textbook, even the most recent editions are about one year behind the technology. Therefore, we have to consider other complimentary sources.

\section{Formal External Training}

We recommend that MIS faculties participate in formal external training such as traditional professional development activities. One type of formal external trainings is IT vendor training. For example, Microsoft, Oracle, SAP, IBM, and SAS all provide some training courses for academics. Some IT vendors charge training fees, while others are offered for free. Workshop and research presentation sessions at academic and industry conferences, such as IACIS (http://www.iacis.org/conference/conference.php), provide another external training format. Academic/industry conferences provide an excellent means for learning about new MIS issues as well as the latest trends in the industry. Formal external training, as a knowledge source, can be reliable and provide high-quality continuing education. However, this approach has its own limitation due to travel funding issues. Universities must cover travel expenses, and currently many higher education institutions are facing financial stress thus funds to support travel are limited. Declining tuition revenue as a result of lower enrollment as well as state mandated higher education budget cuts create a less than optimistic outlook for university and college funded external training. Therefore, MIS faculties need to explore other avenues for professional development.

\section{YouTube and Google}

YouTube has become a "go to" source for anyone needing to gain knowledge of a specific "how to" install, use, or understand products. For example, YouTube can be searched for a video on how to complete subnetting in Cisco's packet tracer program. On the other hand, Google can be used to search the Internet for information on various subjects. Google frequently provides numerous articles on a diverse set of subjects which can be used to further enhance the knowledge base of its users. Compared to traditional formal external training, learning from YouTube and Google is totally free, and can be used at the individual's choice of time and place. For example, when teaching a new Database Administration course, course content can be expanded to introduce students to several new software tools, such as Microsoft SQL Server 2016 Management Studio, Oracle SQL Developer, SAP Crystal Reports 2016, and many others, by using YouTube videos which are useful for demonstrating new features and how to use them. However, there is a negative side to both YouTube and Google. For example, some YouTube content is created by professionals resulting in high-quality videos. However, many other videos are created by amateurs and are both lowquality, outdated and tedious to watch. The quality and usefulness of a YouTube video are unknown before watching it, therefore only one way to determine just how useful a video might be is to actually watch the video. This can be time consuming and inefficient, because there is no gatekeeper to establish standards for e-content. A similar problem exists with Google as some information is substantial and accurate, while other sources are not. For examples, articles sourced by established organizations and industry sources tend to be more useful and reliable compared to blogs by authors with no proper credentials, and organizations with nefarious purposes.

However, there is a more pressing issue - how does an individual know what want to learn, and search for in the first place? For example, a MIS faculty must first somehow have heard about "cisco packet tracer" or "Tableau Desktop Professional" before taking the action to search the terms. Unlike a textbook or traditional formal external trainings, YouTube normally would not tell us what technology is the new and trendy. YouTube and Google are great sources only after we have some solid ideas about what we want to explore and learn. In other words, before engaging in 
learning through YouTube and Google, we need to gather intelligence to find out what is new, trendy, and relevant for teaching MIS. We need to somehow get in touch and connected with the real-world and then we can search it on YouTube and Google and learn about it. To fill in the initial intelligence gap, we propose to engage in FSL and take advantage of all the opportunities presented in front of us.

\section{THEORETICAL BACKGROUND}

Currently, college students face a lot of technology distractions (email, instant messaging, text message, and social network) that demand their precious time and attention. The current generation of students has a very short attention span and is easily distracted by technology (Kroenke \& Boyle, 2016). Kraushaar and Novak (2010) found through their empirical study that college students engage in a substantial amount of multitasking behaviors during class meetings, and distractive (non-course-related) multitasking activities hurt students' academic performance. It is difficult to get students to pay attention and stay focused on the subject matter during lectures. To accommodate today's students' learning style and attract students' attention, teachers need to be innovative in motivating students to learn (Svinicki, 2004). One practical idea is to get students emotionally aroused on the topic by playing relevant videos and pose interesting questions (Kroenke \& Boyle, 2016).

This research addresses the issue of students' short attention span by proposing a new systematic approach called FSL, and to use this new knowledge and insight to enrich MIS courses. With this new tactic, students will receive current, innovative, and unique content. Social learning theory believes that for learning to take place, learners need to pay attention, engage in memory retention process (symbolic encoding and rehearsal and cognitive organization), and have motivation (external or intrinsic) (Bandura, 1977). The word "social" in social learning theory is referring to the context and environment where learning takes place (Taher \& Krishnan, 2014).

Like many innovation endeavors, conducting social learning requires faculties to devote additional time and effort. Given the reality that many faculties are already occupied with regular teaching and preparation, various services tasks, and research projects, how do we motivate and convince faculties, as adult learners, to engage in the social learning activities? Here, we approach it with the theoretical perspectives of adult learning and expectancy-value theory of motivation. Self-directed learning is a key construct in adult learning literature and motivational dimensions are critical aspects of a comprehensive theoretical model (Garrison, 1997). Motivational dimensions address the issue of why adults enter into the learning tasks in the first place. In general, there are three motivation aspects (Eccles \& Wigfield, 2002) as discussed below. First, what is the link between the value (utility) and the task under consideration? In other words, how the task is related to the goal? Normally, we expect that people are more motivated when actions will result in desired outcome. The second motivation aspect is attainment or expectancies for success. It is related to self-efficacy and self-control - how likely that personal ability can lead to succeed and how much is under self-control. The more self-efficacy and self-control that people have, the more motivated they are in undertaking the task. The third motivation aspect is valence - the value of learning outcome, which can be either extrinsic or intrinsic. Intrinsic value can be enjoyment and sense of accomplishment. If the outcome is perceived to be more valuable, people are more likely to be motivated to undertake the action. Cost of the action is another factor involved in the calculation. If the cost of action is low, people are more motivated to act.

\section{THEORETICAL APPLICATION - FACULTY SOCIAL LEARNING}

We define Faculty Social Learning (FSL) as the mindset and process, where faculties proactively engage in various social encounters to observe, learn, and extract new ideas, knowledge, technology, and trend from social contacts for the intended purpose of sharing things learned with students to enrich classroom teaching.

Next, we make a case of FSL based on the social learning theory and expectancy-value theory of motivation. As adult learners, why do faculties engage in the extra activities of social learning in the first place? We argue that social learning will lead to positive outcomes. There are clear benefits of FSL. First and foremost, it will improve classroom teaching by sharing new ideas, knowledge, and skills acquired through FSL. It will better engage students in lively discussions on current issues which can improve the students' mastery of new relevant content. FSL also benefits not just MIS major students, but all business majors. This social learning and teaching approach complements regular teaching and exposes students to new technology and industry trends. It extends students' horizon and enhances 


\section{Issues in Information Systems}

Volume 18, Issue 4, pp. 158-168, 2017

students' interest in the MIS field. Faculties can also better inspire and motivate students. As faculties show their devotion to their teaching profession and their passion for the subject matter, students will be positively affected and look up faculties as their professional role model.

Second, FSL can also produce potential benefits which can be used as external motivation for faculties. As the new knowledge acquired from social learning is disseminated via teaching, students will feel refreshed and more satisfied. In turn, it could improve the faculties' teaching evaluation score given by students. Better teaching evaluation will help faculties' tenure and promotion evaluation. Better teaching evaluation score and the new knowledge and skills will help faculties' future market mobility. On the other hand, it will also lead to faculties' self-fulfillment, enhance self-efficacy and confidence, and boost a positive image. Hence, FSL will bring intrinsic value to faculties.

Third, after we establish the link between FSL and the desired outcome, and confirms that the value of the outcome is positive, next we explore the expectancy aspect of the motivation. Self-efficacy concerns one's general belief that he/she is capable of carrying out the task (Bandura A., 1977). We argue that FSL is entirely within faculties' control and doable, as long as faculties are willing to engage in the activities. Thus, faculties believe that they have the personal ability to succeed in conducting social learning. Moreover, we also want to point out that the cost involved is reasonably low. Monetary cost is minimum, because the social learning that we propose happens locally. The most part of cost is the time and effort faculties put in, which is also manageable.

\section{HOW TO CONDUCT FACULTY SOCIAL LEARNING}

In this study, we provide a unique perspective - faculties acquire new knowledge through social interaction and communication and then share knowledge with students in teaching. FSL refers to the learning that occurs within an informal social context, normally in face-to-face environment. It is very useful for gathering intelligence for further learning from such places as YouTube. For social learning to happen, faculties need to be self-motivate, self-directed, and take initiative to seek opportunities to learn. Some of the social encounters are intentionally planned, while others are unplanned circumstances. Some of these social encounters happen because of institution relationship, for example the established long-term relationship between our MIS department and the MIS department of a local community college. Collaboration brings mutual benefits to both parties. Because our college is part of city's chamber of commerce, we are invited to some meetings and social events. Through the professional contacts we made before, we were invited to other professional and social events. We can get access to certain events because of our positions at our institution. On the other hand, some events are open to the general public. However, it is still important to have the professional contacts in the first place, so we can be aware of those local professional and social events. Even though we are involved with the local business and IT community, we still need to be actively involved and make contributions (such as volunteer for some local events by providing school facility and manpower - students). The continuous engagement in the local community reinforces the relationship and makes it possible for future social learning to take place. In summary, we suggest that faculties should use all the resources and connections provided by the school and also personally reach out to the local community for social learning.

After entering into the social encounters, we purposely and intentionally created, grasped, and took advantages of the opportunities presented to learn more about technology and management. We proactively sought out new knowledge related to MIS in various social contexts. We were also attentive to relevant facts, stories, lessons learned, decision making processes, comments, and opinions in the real-world.

We recommend that social learning should be conducted in a natural setting. We cannot come to a contact's office and directly ask him/her to tell us something about technology so we can share with our classes. Doing so would be unnatural and awkward, and may cause individuals to be defensive. On the other hand, sometimes a person just volunteers to open up and talk continuously about his/her work and technology. What we need to do in such a situation is be attentive, show genuine interest, and encourage the person to carry on the conversation. We should carefully observe, absorb, and accumulate knowledge learned from all social encounters for our purpose - teaching MIS. Subsequently, we can communicate to students what we have learned from college committee meetings, school alumni, college IT staffs, local higher education faculties, and local business and IT professionals. 
To make social learning work, we need to take time to build positive working relationship with all the potential useful contacts (adult returning students with professional experiences, alumni, college IT staffs, local higher education faculties, and local business and IT professionals). We need to show appreciation and respect for the time they spent talking to us as they could have put that time to some alternate use that may not have benefitted us. MIS faculties, like many other professionals, often unconsciously constrain themselves in an ivory tower, losing touch with others. We need to intentionally break the sub-culture barrier to reach out to all potential useful contacts for the benefit of enhancing students' learning. In fact, some people are even willing to share knowledge and help. For example, our college IT manager acknowledges that he would support our teaching by sending his staffs to our classes as guest speakers to share the limited resources. After the social encounters, we normally promptly send an email to express our gratitude to the contacts for their spending time with us.

Symbolic coding into words is better at reinforcing and retaining the knowledge from social learning than simply observing (Taher \& Krishnan, 2014). Therefore, we must write notes during the social encounters or as soon as possible after the informal conversation. The notes must then be transcribed into electronic format in order to have a permanent digital record, which is easier to access. Finally, the transcribed notes must be reviewed before being discussed in the classroom. These steps were taken by us as MIS faculty members.

We recognize that there are limitations to our proposed social learning approach due to school differences in accessibility to potential knowledgeable sources (alumni, business and IT professionals). The geographic location of a school has an impact on the accessibility to local business and IT professionals. For a school residing in a large metropolitan area, it is more convenient to access resources for social learning. On the contrary, for a school located in a remote rural area, it will be very difficult to have face-to-face social interaction with qualified business and IT professionals. The same concern also applies to the access to alumni. Environment and circumstance aside, faculties should make their best effort to reach out for social learning. http://www.eventbrite.com and https://www.meetup.com list local events by city and are useful sources to identify relevant professional and social event hosted within driving distance of a school.

\section{EXAMPLES OF FACULTY SOCIAL LEARNING AND LESSONS LEARNED}

In this section, we present some examples of our social learning. We attempt to demonstrate that through many different types of social encounters, we can learn useful knowledge and share the new knowledge in classroom teaching.

\section{College Committee Meetings}

Useful knowledge can be gained through mundane college committee meetings, if we pay attention and approach them with an open mind. For example, in our business school's committee meeting for preparing AACSB accreditation, we learn two critical concepts. First, our school, or any organization in general, must be mission focused. Different schools may have different but equally appropriate missions. However, the key is that once a mission is agreed upon and established, all the activities should be assessed within the context of the mission - does this activity directly contribute to the mission? In this way, the organization's resources and efforts are directed to the right areas. Second, AACSB does not expect a candidate school to be perfect. AACSB looks for proof that a school is making effort for continuous improvement. Identifying the gaps, planning to deploy resources, and taking actions to rectify the issues are the right approach for continuous improvement. The bottom line is to close the loop! These two important concepts are not only critical for a business school's AACSB accreditation, but also important for the success of any business organization. We use this case as a concrete example in our MIS courses. These examples were simple for our students to understand and internalize because the background was our school.

In another committee meeting, it was discussed that our college's cafeteria food service and cleaning (custodian) services were outsourced. We questioned the decision by the college to hire external sources to run these operations when they could have hired internally instead? The explanation was that in order to operate food service, an organization needed to obtain a state license after successfully completing the food safety compliance program. Due to the state food safety regulation and high compliance cost, it was cheaper to outsource the food service to an established vendor that already had compliance in place. Moreover, food service and cleaning service were not core functions of the college, while teaching and research are the core functions for our college. It is better for an 


\section{Issues in Information Systems}

Volume 18, Issue 4, pp. 158-168, 2017

organization to concentrate its management attention on its core competency and outsource other non-critical functions. This is a great case that our students can relate to in our discussion of organizational strategy and outsourcing.

\section{Students and Alumni}

Surprisingly, sometimes we could even learn interesting knowledge from our own students and alumni. Often those students are non-traditional adult students, who have extensive professional experiences. Causal conversions with them can uncover some new and useful facts, technology, and ideas.

In one of our database classes, an adult student, who works for a large manufacture firm told us that his firm uses Apache software foundation's Cassandra as database for mobile applications. His firm does have regular relational databases for SAP and AS400 systems. His firm copies the data into Cassandra as a database relay server. Then mobile applications interface with Cassandra. The reason for this setup is that Cassandra has the advantage of fast throughput in and out. This case is very useful when discuss the idea of NoSQL movement and big data.

Another student told us a real story related to one of his friends, an IT guy. The IT guy did not apply software patch promptly and thus caused his company's database system to be exploited and compromised. After verifying the fact, the company fired him for his negligence. This case serves as a good example in discussions of information security and IT professional's responsibility.

Another student told us of a legend he heard about Steve Jobs (co-founder of Apple). One day during a company meeting with high-level management, Steve Jobs threw a new iPhone into a fish tank in front of the meeting attendees. Steve Jobs pointed to the bubbles and made a point that there were still empty space inside the iPhone. Hence, there was still room for improvement to make iPhone thinner and more compact. This story makes a great teaching case of continuous improvement and pursuit of product perfection.

Through a casual conversation, we learned that one student is currently preparing to take Cisco CCNA certification exam. He shared with us the textbook (Odom, 2016) he is using. Moreover, speaking from his unique personal experience, he strongly recommended that students should have hands-on experience with real Cisco hardware. According to him, GNS3 (a Cisco network simulation software) is great for beginners to learn about Cisco network. With GNS3 one can deal with more than $85 \%$ of CCNA test content and pass it. However, there is still a big difference between using GNS3 simulation only and having hands-on experience with real network hardware. GNS3 may only do about $40 \%$ of what real hardware is capable of doing. By its very nature, GNS3 does not crash or get into trouble. However, with real hardware, students will encounter all kinds of real problems and have to figure out many things and solve real problems. Through the process of solving real problems with hardware, one can learn more and gain deeper practical knowledge. These are valuable tips for helping students prepare for the Cisco CCNA certification exam and become a network professional with practical skills.

We learned from an alumni of our school that mainframe computing somehow is becoming important again in this cloud computing era. The alumni explained to us that for many businesses it is simply too costly to rewrite mainframe business applications. So businesses are still maintaining and running those mainframe legacy systems today. Moreover, many senior experienced staff with mainframe skills are retiring within the next decade, causing a pipeline issue. Therefore, in the foreseeable future, there is a clear demand for college graduates with mainframe skills to support those existing mainframe systems. MIS programs are encouraged to consider training students for this niche market with COBOL and RPG programming, or IBM zSystems skills.

\section{College IT Staffs}

Our college IT manager is a great and convenient source for social learning. We have invited him and his staffs to come to our MIS classes to engage in discussions about IT. We have also engaged in informal conversations with the IT manager and his staffs and learned many valuable facts, ideas, decision making processes, and management thinking. Next, we report some important lessons we learned. 


\section{Issues in Information Systems}

Volume 18, Issue 4, pp. 158-168, 2017

\section{Database Management}

In the 1990s, the college's register's work was mainly manual and paper-based at that time. Computer brings automation of the business process. Subsequently, the college employed a mainframe legacy COBOL system for its operations. The COBOL system does not require a lot of memory and disk space. The college then switched to Oracle relational database, and within a month it reaches the limitation of hardware. More memory and disk had to be acquired in order to keep the Oracle system running. Oracle database is well engineered, and very stable and robust. If something goes wrong, it is very likely because of human error, not Oracle database's problem. Oracle on Unix/Linux system is a very good choice for enterprise level database. The college used to run HP Unix on its server hardware. After Oracle acquired Sun Microsystem, Oracle promoted its own Sun Microsystem hardware/operating system (OS) and discouraged its clients to use HP Unix. College IT plans to migrate to open source Red Hat Linux. Red Hat Linux is a fine operating system. Red Hat Linux and Windows Server each takes about half of the server OS market. Moving to Red Hat Linux will save the college some money on software license fees. The College IT used to have BSD - an open source operating system. However, since the technician that was in charge of it left, no one is comfortable with BSD. It was decided to migrate to Red Hat Linux.

Our college has a student degree audit system, which uses Oracle databases, and is maintained by the college IT department. Blackboard, a learning management system, is also maintained by the college IT department. In the college, the student information system is powered by PeopleSoft (Oracle) databases. It has almost 3000 tables, many views, triggers, store procedures, Java codes, and packages. A view is like one big virtual table having very complex SQL behind. Sometimes a view joins 15 to 25 tables. The benefit of a view is that it is written once with very complex $\mathrm{SQL}$, and after that there is no need to rewrite it again. A package is a bundle of objects in a database. They are relevant functions that are often being used. A package facilitates code reuse.

Traditional roles of DBA (database administrator) include: install and update DBMS, resource allocation (disk and memory), performance tuning, user administration and security (who gets to access to which database, audit, and permission control such as "who can change grades?" and "who can change the money amounts in student's account?"), and backup and recovery.

\section{Security Issue}

Our college IT manager once told us a story regarding a different state college's security mishap. One day that college was having an unexpected security audit. In that college, it was a common knowledge that an account for Crystal report was used to connect to the Oracle database for generating all the reports. An IT auditor parked his car in the parking lot of that college. He called the help desk saying that he forgot the password for the Crystal report account. The help desk staff gave him the password. The auditor setup ODBC connection using the account/password and downloaded the data from the Oracle database via Excel. Then the auditor presented the downloaded data to the president of that college. This real story highlights how vulnerable an information system could be. Without proper security policy, process, and technology in place, a college network and system is prone to be exploited by hackers.

\section{System Integration Issue}

Our college IT manager told us that he had heard about system integration issues for more than 25 years. So it is not a new problem at all. After all these decades, it is still an unsolved problem. However it is getting better. One common example of information systems integration issue in a higher education context is that student management information system and Blackboard are not integrated. So after final exams, instructors have to manually enter grades in both systems, because the two systems are not synchronized and connected. Due to the lack of system integration, not only additional human labor is required for the work, there is also a heightened chances of human error and inconsistency between systems.

\section{Centralization and Decentralization}

In 1990s the idea of decentralization took hold. The main idea is to put servers closer to end users to have better performance and segmentation of network traffic. After 2000, as network technology matures and Internet security risk becomes more serious, the trend is to centralize servers to data centers. The management and control become 


\section{Issues in Information Systems}

Volume 18, Issue 4, pp. 158-168, 2017

central again for servers. Nowadays only some large research universities have school level IT staffs directly supporting their departmental applications. Small colleges like our college moved away from departmental IT and centralized the IT function.

\section{Local Higher Education Faculties}

As mentioned before, due to the pre-existing relationship between our school and a local community college, we were able to meet a network expert, the director of Cisco Regional Networking Academy, to discuss and exchange tips for teaching network.

From the conversation, we find out that our course "Introduction to Networks" is much related to Cisco CCENT, which is easier than CCNA. CCNA asks scenario-based questions. For example, a help-desk staff receives a phone call reporting a problem and what to do to solve the problem. It used to have 55 questions and 75 minutes. CCNA is very useful for students looking for a job in a network area. The director also sees a lot of requests for A+ certification. The director also said that any certification related to security is hot, ranging from security+ to CISSP. In the most difficult and valuable Cisco certification exam, a candidate is presented with a bunch of routers, switches, and wires. $\mathrm{He} / \mathrm{she}$ is given three hours to fix the real hardware problems.

The Director also proposed the idea of a hands-on lecture approach when teaching the network class. It is not pure textbook-based, but real-world scenario based. He suggests that students should always think from a customer or client's perspective to setup a network and configure a router. He believes that teachers should test students on network applications, not on tools. His teaching method includes first reading a chapter from the Cisco textbook and writing down a few points. He then lectures on those points. He also uses Cisco quizzes and Cisco Packet Tracer 6.2iv (a network simulation software) activities. He gives students a printed sheet with topology and asks students to build a network from scratch in Packet Tracer. After about 20 minutes, he walks around the classroom and grades in real time, or he asks students to submit their Packet Tracer files to Blackboard for grading. He also gives students paper-based Cisco quizzes and manually grades them. He is considering putting Cisco quizzes on Blackboard to reduce manual grading work. He highly recommends that we watch Packet Tracer tutorials and play with Packet Tracer. Packet Tracers' help file is also very useful. He cautions us that Packet Tracer supports only a subset of Cisco commands. On the other hand, the real Cisco physical hardware (router and switch) supports the full set of Cisco commands. When connecting to a Cisco router or switch through a physical console cable and typing in command "?", all the Cisco commands can be displayed. In Packet Tracer, we can pick the type of routers and switches like Cisco 2600 series $(2620 \mathrm{XM})$.

He also suggests that we have students do a hands-on hardware project. With two routers, two switches, and two PCs, students can setup a realistic functioning network. Moreover, students can see how real routers and switches look like, front and back side. This will help students' understanding what they see the physical equipment with Cisco Packet Tracer. Due to limited number of routers and switches available for teaching, he suggests that we can organize students into two groups. In one class meeting, we can ask group $A$ to work on the hands-on hardware project and group $B$ works on a Packet Tracer activity. Then in the next class meeting, we can switch around the group assignment. In this way, every student will get a chance to work on the hands-on hardware project in a small group.

The Director also acknowledged that Wireshark was a very good packet sniffer software, but he cautioned us to be very careful that some students may use it for bad purpose, such as sniffing password. He acknowledged that at his college a sniffing password scandal once got as far as the president's office. Therefore, he suggested to us to only do a demo of Wireshark and show students the live traffic packets, such as broadcast. He also recommended that we try to get state government agencies to donate their old routers and switches to our school, whenever they update their equipment.

\section{Local Business and IT Professionals}

\section{Local Small Business Owner}

A local small business owner told us that some college graduates do not have Microsoft Office competency. Some graduates cannot put simple multiplication in Excel. Word template is very useful in small firms. Excel can be used 


\section{Issues in Information Systems}

Volume 18, Issue 4, pp. 158-168, 2017

to facilitate administrative work. Some MBA students do not know how to use Microsoft Office. The bigger issue is that some MBA students are not curious enough about learning how to use Microsoft Office! However, the basic productivity suite like Microsoft Office are critical skills sought after in the marketplace. We should not blindly assume all business students are proficient in Microsoft Office.

\section{Local Business Entrepreneur}

We learned the idea and practice of co-working from a local business entrepreneur. Co-working is a new innovative idea for employees from different firms work together in the same physical space. The rationale is that if people are physically working together in a building, then they are more likely to have social interactions, such as asking questions and helping each other. Therefore, co-working will facilitate bouncing ideas and increasing innovation. In our city downtown area, three houses next to each other are designated and developed as a co-working space - like an incubator. Co-working will facilitate startup firms. The first house is the place for generating creative ideas. The second house is used for developing products. The third house is used for finally launching a business.

\section{Local IT Professionals}

Through various occasions, local professional and social events, we got access to IT professionals and engaged in informal conversations. Next, we present some of the lessons we learned from the social interactions.

An IT professional works for a large firm as a DBA. His team is going to be merged with another group of DBAs. His firm has four live database servers running at the same time, replicating each other. In addition to data, applications are also replicated in four servers. Two servers are located in Georgia and two servers are located in Florida. It is indeed very expensive for the four-way redundancy. However, it is very safe. In case a disaster strikes one site and destroys all data and applications in one site, another site can immediately take over and continues running the business. Sometimes, one site is brought down for maintenance or update, the other site is switched to be the main production database server. Because of virtual IP, it is transparent to users. The production system is on $24 \mathrm{X} 7$ (24 hours a day, 7 days a week). Most times his work is not stressful, but emergencies, such as some queries running too slow, do happen. In that case, a DBA needs to kill the process. But before a DBA kills a process, he/she needs to ask permission. Sometimes a database runs out of disk space limit. One case was that the data type of a data column was auto increasing number, and the original design was using integer. But one day, it ran out of all integer in the range. DBAs had to upgrade it from integer to big integer in Oracle. Since it is a big table, it takes more than two days to perform the change. Later DBAs change a new strategy to create a brand new table with big integer and then slowly copied old data into the new table. To support production database system, each DBA takes a pager for a week to be on call. That week is stressful because of the responsibility to answer questions 24X7. The firm has a lot of Oracle databases, some Microsoft SQL Server databases, some Sybase databases, some Oracle MySQL databases, and some PostgreSQL databases. Because MySQL is open source and free of license fee, it saves a lot of money. The firm has headquarters in both UK and US. It just signed a contract in Beijing, China, and acquired 16 firms in China. It also plans to expand to India and Brazil. Many managers and senior people earn between $\$ 110,000$ and $\$ 120,000$ ! Every year there is 2 to 3 percent of salary increase. In addition to salary, the firm has a maximum of 36 days' vacation. Sometimes, the firm allows IT employee to work at home via telecommute. The IT professional's account of his work as a DBA, his company's technology, as well as the general benefits of working in a large firm are great teaching materials in Database course and can be used as an inspiring case.

In a different social encounter, we learned some new technologies from an IT professional. For a big data center, automation script is very useful. Automation script can be used to configure servers, networks, subnets, and load balance. Nowadays, a DBA can write a script to set up even a whole virtual data center. His firm opens a new division in Europe. IT people in his firm just ran a script to create a virtual data center in an unnamed European location near his firm's Europe facility. It is very easy to adjust data center configuration by just tweaking script codes. Amazon's public cloud provides a service called virtual private cloud. By using Amazon auto scaling feature, IT people can set up rules and parameters such as "if CPU usage $>90 \%$ then add more virtual machines". Some companies try private cloud open stack technology and find out that it is not stable. So they switch back to Amazon public cloud. Netflix is using Amazon cloud infrastructure. Continuous integration and deployment are new hot concepts in the IT world. Traditionally an information system update follows the fixed process of new development $\rightarrow$ testing $\rightarrow$ package into 


\section{Issues in Information Systems}

Volume 18, Issue 4, pp. 158-168, 2017

a patch $\rightarrow$ roll-out in production system. This batch-mode process is lengthy and has a long lead time. In the cloud computing environment, updates are continuously rolled out without long lead time.

In another social encounter, we learned the new ideas of agile software development and online coding group from multiple local IT professionals.

Agile method is in trend in the real-world. An IT professional suggested to us to forget about the traditional SDLC (system development life cycle), structured approach, and waterfall method. In modern software development, small sprints and an iterative approach are more realistic, as requirements are always changing. Agile approach reduces a lot of wasted work. Agile approach helps improve information system quality for the organization's inventory information system. In private sector agile approach increases speed to market. Agile approach is also more effective. SDLC has an inevitable problem - immediately after release, customers/clients have new requests and the information system needs to be updated. In today's environment, IT people need to be more social and a team player. The idea is to move programmers closer to clients. Being part of the team, talking to clients to gather requirements, and engaging clients are new critical skills. The old stereotype of a computer geek working alone in basement cubicle is no longer valid. In old days programmers were handed down requirements and then instructed to code. Nowadays programmers need to reach out to the clients. It is acceptable to be an average programmer with good social skills.

To motivate people to learn computer programming, physical (face-to-face) or online study group are proving to be helpful. Programmers of different skill levels work together and ask questions via online chat. Code buddy (https://codebuddies.org/) is such a website facilitating people to learn coding through online chat and scheduled hangouts. Free Code camp (https://www.freecodecamp.com) is another online community with free tutorials. It promotes the idea of "launch your developer career by learning to code and helping nonprofits".

\section{SUMMARY}

Teaching MIS is challenging because the field is undergoing rapid changes. To teach students updated and current content, we examine several conventional knowledge sources - textbooks, formal external training, and YouTube and Google. However, these sources have their own limitations. We propose a new approach - FSL and enrichment of MIS courses. Based on adult self-directed learning theory, motivation theory, and social learning theory, we make a case for FSL. Next, we describe how to conduct FSL and provide detailed suggestions based on our first-hand experiences. We recommend faculties to proactively reach out to all potential useful contacts (adult returning students with professional experiences, school alumni, college IT staffs, local higher education faculties, and local business and IT professionals) for social learning. By engaging in informal conversations with them and attending local professional and social events, we can learn new knowledge, ideas, and technology useful for teaching. Then we can share new knowledge learned from social learning with our students. The marginal cost of FSL is acceptable, while the marginal return on investment of faculty time and effort is considerably large. Therefore, our recommended social learning approach is efficient, practical, and doable for most MIS faculties. With reasonable efforts, faculties can easily implement the social learning approach. This study contributes to the literature not only with the proposed FSL approach, but also with the reported knowledge that we gained from our social learning practice. Faculties can use the materials presented in this paper for their own teaching. We hope that the FSL idea and the examples of our social learning are useful for MIS faculties in their pursuit of enriching MIS courses. In a future study, we plan to explore new ways of FSL in the online context.

\section{REFERENCES}

Bandura, A. (1977). Self-efficacy: Toward a Unifying Theory of Behavioral Change. Psychological Review, 84(2), $191-215$.

Bandura, A. (1977). Social Learning Theory. Englewood Cliffs, NJ, U.S.A.: Prentice-Hall.

Eccles, J. S., \& Wigfield, A. (2002). Motivational beliefs, values, and goals. Annual Review Of Psychology, 53(1), 109-32. Retrieved May 16, 2017, from http://outreach.mines.edu/cont_ed/Eng-Edu/eccles.pdf 


\section{Issues in Information Systems}

Volume 18, Issue 4, pp. 158-168, 2017

Garrison, D. R. (1997, Fall). Self-directed learning: Toward a comprehensive model. Adult Education Quarterly, 48(1), 18-33. Retrieved May 16, 2017, from http://journals.sagepub.com/doi/pdf/10.1177/074171369704800103

Kraushaar, J. M., \& Novak, D. C. (2010, June). Examining the Affects of Student Multitasking With Laptops During the Lecture. Journal of Information Systems Education, 21(2), 241-251. Retrieved from http://jise.org/Volume21/21-2/Pdf/vol21-2-pg241.pdf

Kroenke, D. M., \& Boyle, R. J. (2016). Experiencing MIS (7th ed.). Upper Saddle River, New Jersey, U.S.A.: Pearson.

Kroenke, D. M., Auer, D. J., Vandenberg, S. L., \& Yoder, R. C. (2018). Database Concepts (8th ed.). Hoboken, New Jersey, U.S.A.: Pearson.

Odom, W. (2016). CCENT/CCNA ICND1 100-105 Official Cert Guide. Indianapolis, Indiana, U.S.A.: Cisco Press. Retrieved from http://www.ciscopress.com/title/9781587205804

Svinicki, M. (2004). Learning and Motivation in the Postsecondary Classroom (1st ed.). New York, New York, U.S.A.: Anker Publishing.

Taher, M., \& Krishnan, S. (2014, December 4). Social Learning Theory. Retrieved May 16, 2017, from istheory.byu.edu: https://istheory.byu.edu/wiki/Social_learning_theory 